Article

\title{
A Human-Needs-Based Dynamics to Simulate Technology Policy and Its Effects on Both Business Success and Human Happiness
}

\author{
Jong-Yeon Lim ${ }^{1}$, Sun Hi Yoo ${ }^{2}$ and DongKyu Won ${ }^{2, *}$ \\ 1 College of Life Science \& Biotechnology, Korea University, Seongbuk-gu, Seoul 02841, Korea; \\ jylim0317@gmail.com \\ 2 Seoul Branch Office, Korea Institute of Science and Technology Information, Seoul 02456, Korea; \\ sunny@kisti.re.kr \\ * Correspondence: dkwon@kisti.re.kr; Tel.: +82-2-3299-6053 \\ Academic Editor: Giuseppe Ioppolo \\ Received: 15 July 2016; Accepted: 16 November 2016; Published: 25 November 2016
}

\begin{abstract}
This paper focuses on how human needs are reflected in the market and how several technological and political policies affect the market share of government-supported industries, as well as the satisfaction of human desires and consequent happiness. In this paper, we seek to understand the dynamics of consumer decision-making processes in relation to technology products in the market. In this study, we present a new marketing model based on human needs, wants, and demands, and focus on both holistic and social perspectives. We have shown that human-based policy dynamics and sustainable human happiness can be realized by stimulating national policies for consumer happiness in the human-needs-based sector, e.g., the healthcare industry.
\end{abstract}

Keywords: human needs; human happiness; market dynamics; consumer decision-making; sustainable market policy

\section{Introduction}

Recently, improving the quality of life and welfare of citizens has been considered in the development of national and enterprise policies. Happiness is a sign that human needs are met. Average happiness has increased in most countries over the last decade. Still, happiness has not increased everywhere and most countries are far from achieving an optimal level of happiness. There seems to be a need for rethinking how we should shape our society and our lives in a happiness-increasing direction. Many researchers believe that some very powerful technologies will be developed during the coming decades, including biotechnology, nanotechnology, artificial intelligence, and the like. However, little attention has been given to how these can be used to improve human happiness and welfare as well as enhancing our emotional capacities.

Will the nation as a whole achieve greater happiness as a result of increased national policies of science and technology? The government exists for the purpose of serving the people. One of the primary goals of technology policy should be to assist in this pursuit. Therefore this paper focuses on how human needs are reflected in the market and how several technological and political policies affect the market share of government-supported industries, as well as the satisfaction of human desires and consequent happiness.

In this study, we explored factors that affect the relationship between national R\&D policy and human happiness. We assumed that social marketing practices based on improving human happiness affect long-term customer satisfaction (since it is known that perceived happiness is the main driver of customer satisfaction) [1]. 


\section{Conceptual Framework}

When does a consumer become loyal over the long term? Consumer happiness occurs when a customer feels happiness or joy and this happens prior to the development of customer loyalty [2]. There is currently research being conducted on customer happiness to find methods of improvement in this regard. Seligman defined happiness as 'authentic happiness', which focused on the lasting experience of the feeling [3]. Human needs are basic requirements for life and include food, clothing, and shelter. Without these needs, humans simply cannot survive. Today, education and healthcare have both become an extension of these needs. On the other hand, consumer satisfaction is being discussed separately from the consumer happiness mentioned above.

In this study, we present a new marketing model based on human needs, wants, and demands from both holistic and social perspectives (Figure 1). We define needs as physical drives (i.e., food, safety, shelter) or mental requirements (belonging, affection, and self-expression) that contribute to a state of well-being. Wants are defined as socially accepted ways to meet needs. Finally, demands are defined as wants that are supported by resources (e.g., money) and allow these wants to be fulfilled.

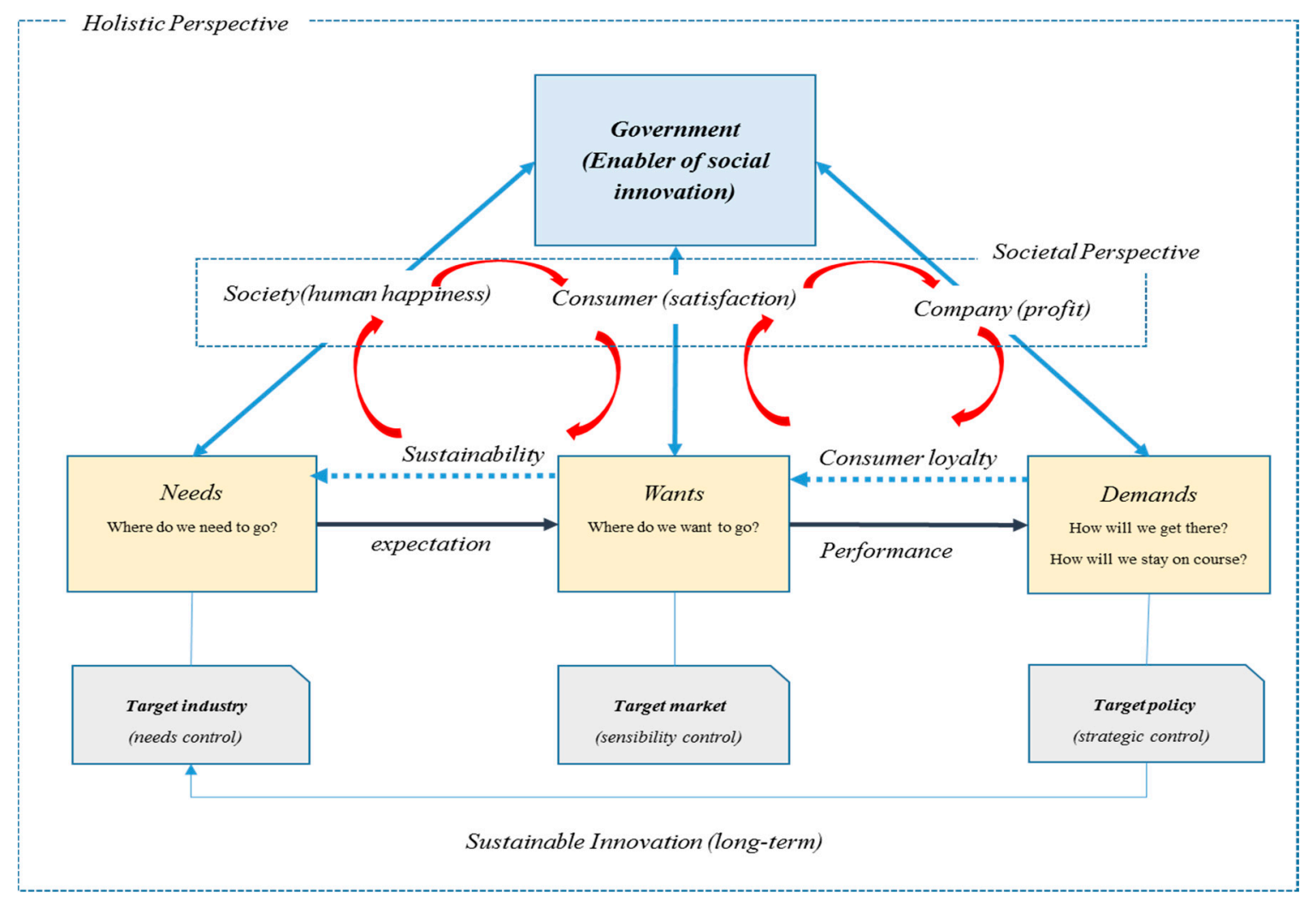

Figure 1. Holistic social marketing conceptual framework.

In this model, we assumed that the core value is consumer needs, which are embodied in wants and demands. By adjusting government policies, both consumer satisfaction and human happiness (well-being) can be maximized at each stage (Figure 1). The best performance of this model is observed when there is prolonged customer loyalty and sustainability in the market.

A new marketing model provides a three-dimensional conceptual space for holistic and social perspective comprising the dimensions of sensus, locus, and focus [4]. In this paper, sensus is a compound word of sense and focus. We uncover cases to determine the industry, find the market in the industry by exploring the sense, and then go through the process of testing the new policy in that market (Figure 2). 


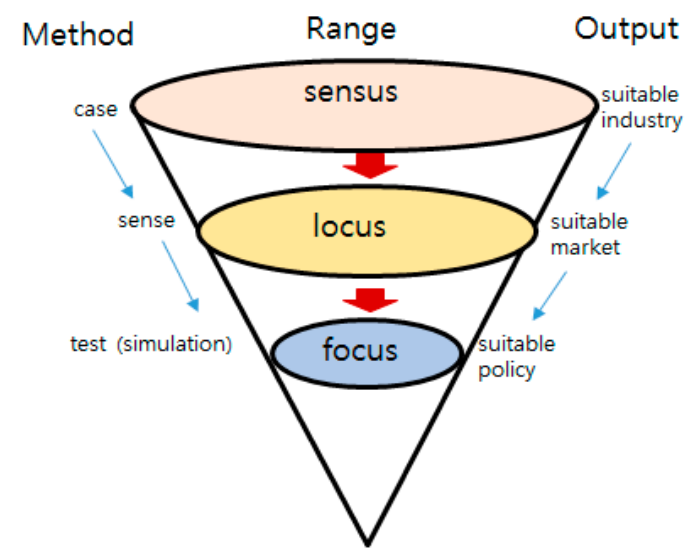

Figure 2. Method, range and output of research.

A first dimension is the sensus of human needs-the degree of sensitivity to changes in human needs while we are interacting with the industry. A locus of human wants, meanwhile (in Latin, the word means "place"), is a site or location. As is the case with sensus, the locus can be a specific place or part of the sensus. The third dimension, focus applies policy simulations to industries and markets that have been discovered in the upper dimension. This will ultimately ensure sustainable growth potential.

\section{Research Model}

The research model in this paper proceeds as follows (Figure 3).
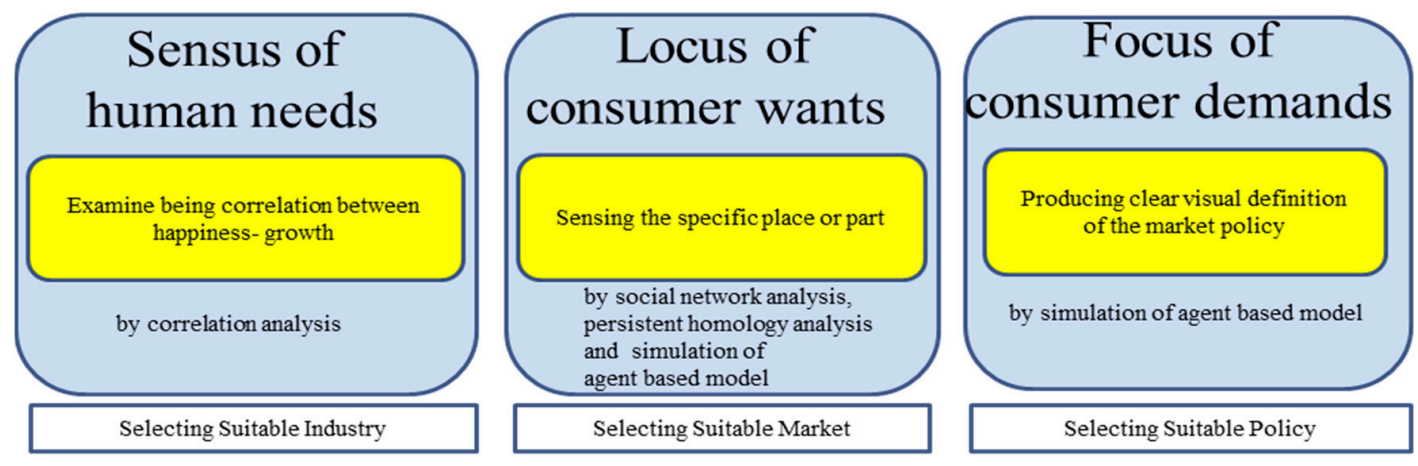

Figure 3. Research model.

Section 4.1 examines the sensus of human needs, which is the industry setting that best fits the people of the country. Here, Korea is taken as an example. Section 4.2 examines the locus of human wants, sensing the specific place or part in the sensus by social network analysis, persistent homology analysis, and simulation of an agent-based model [4]. Section 4.3 examines the focus of demands, meaning the state or quality of having or producing a clear visual definition of market policy by simulation of an agent-based model.

\section{Methods and Data}

\subsection{Sensus of Human Needs}

We analyzed the relationship between national happiness and bio-innovation indices across 56 countries, which were matched to each other using the investigation reported by ITIF and the “World Happiness Report" (Table 1) [5]. 
Table 1. National happiness index and bio-innovation index.

\begin{tabular}{|c|c|c|c|c|c|c|c|c|c|c|c|}
\hline Country & Happiness * & $\begin{array}{l}\text { R\&D Composite } \\
\text { Score }\end{array}$ & $\begin{array}{l}\text { Government } \\
\text { Health R\&D }\end{array}$ & $\begin{array}{c}\text { Government } \\
\text { R\&D as a } \\
\text { Share of GDP }\end{array}$ & $\begin{array}{l}\text { Extent of Price } \\
\text { Controls }\end{array}$ & Country & Happiness & $\begin{array}{l}\text { R\&D Composite } \\
\text { Score }\end{array}$ & $\begin{array}{l}\text { Government } \\
\text { Health R\&D }\end{array}$ & $\begin{array}{c}\text { Government } \\
\text { R\&D as a } \\
\text { Share of GDP }\end{array}$ & $\begin{array}{l}\text { Extent of Price } \\
\text { Controls } * *\end{array}$ \\
\hline Denmark & 1 & 1 & 2 & 3 & 3 & Spain & 29 & 6 & 4 & 24 & 3 \\
\hline Switzerland & 2 & 13 & 13 & 10 & 1 & Slovakia & 30 & 27 & 14 & 37 & 2 \\
\hline Iceland & 3 & 17 & 35 & 2 & 2 & Malaysia & 31 & 41 & 40 & 41 & 2 \\
\hline Norway & 4 & 2 & 6 & 8 & 3 & Italy & 32 & 24 & 21 & 26 & 2 \\
\hline Finland & 5 & 28 & 41 & 7 & 2 & Japan & 33 & 34 & 38 & 21 & 2 \\
\hline Canada & 6 & 32 & 33 & 20 & 2 & Russia & 34 & 39 & 51 & 14 & 2 \\
\hline Netherlands & 7 & 23 & 28 & 18 & 2 & Poland & 35 & 14 & 10 & 31 & 2 \\
\hline New Zealand & 8 & 25 & 22 & 27 & 2 & South Korea & 36 & 21 & 39 & 6 & 2 \\
\hline Australia & 9 & 31 & 18 & 38 & 3 & Lithuania & 37 & 43 & 45 & 42 & 2 \\
\hline Sweden & 10 & 3 & 9 & 4 & 2 & Slovenia & 38 & 15 & 16 & 16 & 2 \\
\hline Israel & 11 & 52 & 55 & 29 & 1 & Peru & 39 & 46 & 37 & 53 & 2 \\
\hline Austria & 12 & 12 & 25 & 1 & 2 & Latvia & 40 & 51 & 47 & 55 & 2 \\
\hline United States & 13 & 7 & 12 & 5 & 1 & Romania & 41 & 47 & 44 & 46 & 2 \\
\hline Costa Rica & 14 & 53 & 52 & 44 & 2 & Estonia & 42 & 16 & 24 & 11 & 2 \\
\hline Germany & 15 & 22 & 34 & 13 & 2 & Hong Kong & 43 & 50 & 50 & 43 & 3 \\
\hline Brazil & 16 & 37 & 43 & 22 & 2 & Turkey & 44 & 56 & 56 & 48 & 2 \\
\hline Belgium & 17 & 48 & 53 & 28 & 2 & Indonesia & 45 & 44 & 30 & 51 & 1 \\
\hline Ireland & 18 & 38 & 36 & 35 & 3 & Philippines & 46 & 54 & 48 & 56 & 2 \\
\hline Mexico & 19 & 35 & 27 & 40 & 1 & China & 47 & 26 & 19 & 32 & 3 \\
\hline Singapore & 20 & 9 & 11 & 9 & 1 & Hungary & 48 & 18 & 15 & 25 & 2 \\
\hline United Kingdom & 21 & 4 & 1 & 30 & 3 & Portugal & 49 & 8 & 8 & 19 & 2 \\
\hline Chile & 22 & 33 & 17 & 50 & 2 & Vietnam & 50 & 40 & 31 & 52 & 2 \\
\hline Argentina & 23 & 36 & 32 & 34 & 1 & Greece & 51 & 29 & 26 & 33 & 2 \\
\hline Czech Republic & 24 & 19 & 23 & 17 & 2 & South Africa & 52 & 30 & 20 & 39 & 3 \\
\hline Colombia & 25 & 11 & 3 & 49 & 2 & India & 53 & 42 & 49 & 23 & 3 \\
\hline France & 26 & 20 & 29 & 12 & 3 & Kenya & 54 & 10 & 5 & 45 & 2 \\
\hline Thailand & 27 & 49 & 42 & 54 & 3 & Ukraine & 55 & 45 & 46 & 36 & 2 \\
\hline Taiwan & 28 & 5 & 7 & 15 & 1 & Bulgaria & 56 & 55 & 54 & 47 & 2 \\
\hline
\end{tabular}

${ }^{*}$ This is a ranking of the sampled countries, not the actual order; ${ }^{* *}$ Extent of Price Controls: 1 , low; 2 , moderate; 3, high; Sources: [6,7]. 
We examine the aggregate relationship by structural modeling using the PLS-SEM algorithm [8]. The hypothesis of this analysis is as follows.

Hypothesis 1. Healthcare capabilities positively influence the long-term performance of technology investments, which is regarded as a critical factor of human happiness, and work by deploying resources with the capacity to create value (Figure 4).

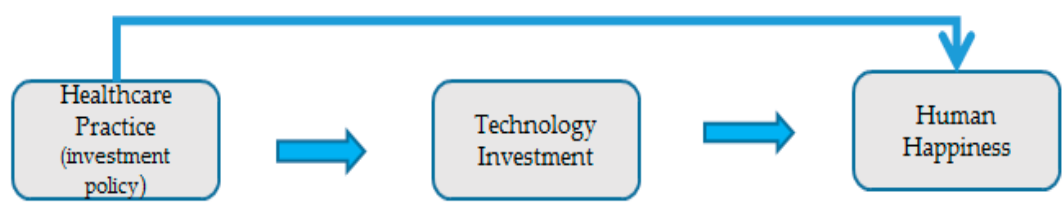

Figure 4. The direct and mediated relationships that enhance human happiness.

The results of confirmatory factor analysis (CFA) and construct reliability (CR) are shown in Tables 2 and 3 . They were estimated to be wider than a 99\% confidence level [9].

Table 2. Average variance extracted (AVE).

\begin{tabular}{cccccc}
\hline & Original Sample & Sample Mean & Standard Deviation & T Statistics & $p$ Value \\
\hline Healthcare Investment & 0.517 & 0.544 & 0.045 & 9.597 & 0.000 \\
Technology Investment & 0.834 & 0.831 & 0.050 & 16.657 & 0.000 \\
\hline
\end{tabular}

Table 3. Composite reliability.

\begin{tabular}{lccccc}
\hline & Original Sample & Sample Mean & Standard Deviation & $\boldsymbol{T}$ Statistics & $p$ Value \\
\hline Healthcare Investment & 0.642 & 0.635 & 0.096 & 6.680 & 0.000 \\
Technology Investment & 0.910 & 0.908 & 0.030 & 30.382 & 0.000 \\
\hline
\end{tabular}

In Table 4, all the direct relationships postulated in this analysis were found to be positive and significant (at a 0.001 level of significance), except the hypothesis that proposed a positive influence of healthcare investment on human happiness, which was found to be insignificant.

Table 4. Direct path coefficients.

\begin{tabular}{lcccc}
\hline & Original Sample $(\boldsymbol{\beta})$ & Standard Deviation & $\boldsymbol{T}$ Statistics & $p$ Value \\
\hline $\begin{array}{l}\text { Healthcare Investment } \\
\rightarrow \text { Human Happiness }\end{array}$ & -0.290 & 0.184 & 1.582 & 0.114 \\
\hline $\begin{array}{l}\text { Technology Investment } \\
->\text { Human Happiness }\end{array}$ & 0.655 & 0.149 & 4.382 & 0.000 \\
\hline $\begin{array}{l}\text { Healthcare Investment } \\
->\text { Technology Investment }\end{array}$ & 0.739 & 0.040 & 18.556 & 0.000 \\
\hline
\end{tabular}

Figure 5 shows that "Healthcare Investment" indirectly affects "Human Happiness" through "Technology Investment". Therefore, this analysis established healthcare investment as one of the critical requirements of human happiness. 


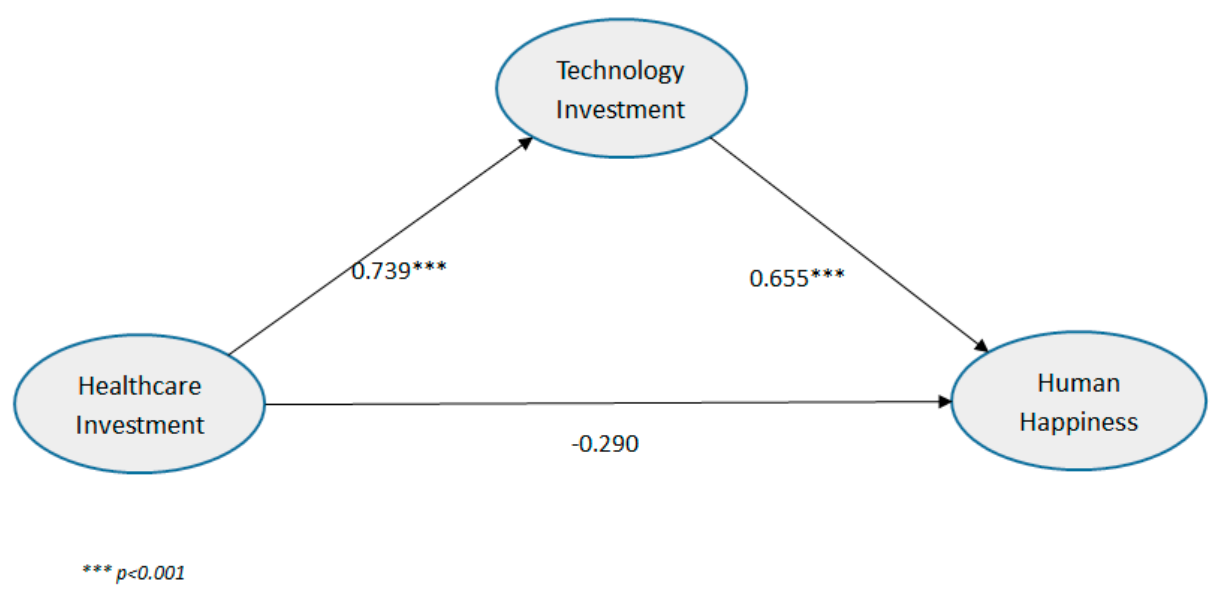

Figure 5. Path network among the various factors.

\subsection{Locus of Consumer Wants}

\subsubsection{Bio-Issue Clustering}

We analyzed co-occurrence patterns between significant words to identify potential market needs within the healthcare industry. Our text data consist of the titles of healthcare sectors found in the BRIC (Biology Research Information Center) database (http:/ /www.ibric.org) from 2009 to 2015 (Figure 6) [10].

We first performed a persistent homology analysis to determine the number of clusters. The reason for this analysis is that there is no objective criterion for how many clusters should be set in the cluster analysis. The notion of "persistent homology" is the algorithms for topological invariants across various scales of a topological manifold in TDA (Topology Data Analysis) [11]. A "barcode" plot is a qualitative visualization of a homology group. The $x$-axis in Figure 7 represents the scale parameter " $\mathrm{e}$ " and the $y$-axis is an arbitrary ordering of homology generators. In Figure 7, the straight line that survives to the end is meaningful even though the $y$-axis increases clockwise, while short lines are just topological noise [12]. The number of meaningful long lines is 12. This is because we have to choose the place where the gap between lines is the largest (Figure 7).

Here, we can see 12 of the main topics in these word clusters. The vertical distance represents the degree to which semantic relationships were included. The co-occurrence words-based, social network analysis is one of the simplest topic models and, as such, is very widely used. The model is considered psychological, which means such models represent a sort of social perspective (Figure 8).

\subsubsection{Hysteresis Effect Model for Bio-Issue Analysis}

We use the cluster above to construct a hysteresis effect model to see how the relationship between elements changes with changes in external circumstances. Here, hysteresis means that the state of the object depends on the state of the past. In other words, depending on the strength of the system in the past, the recovery paths are different. In the figure, "a" represents the path of the smallest bond and "b" represents the path for the large bond (Figure 9).

This model is a representation of the major factors. The nodes in this model represent the symptoms of major needs for the market. These factors are pharmaceutical investment, clinical infrastructure, bio-technology development, health food development, R\&D investment, expanding commercialization, the development of medical equipment, new drug infrastructure, healthcare development, fostering new industries, technology development, and medical complex development. These issues have a direct causal influence on other factors; this is called the causal network perspective [13]. 


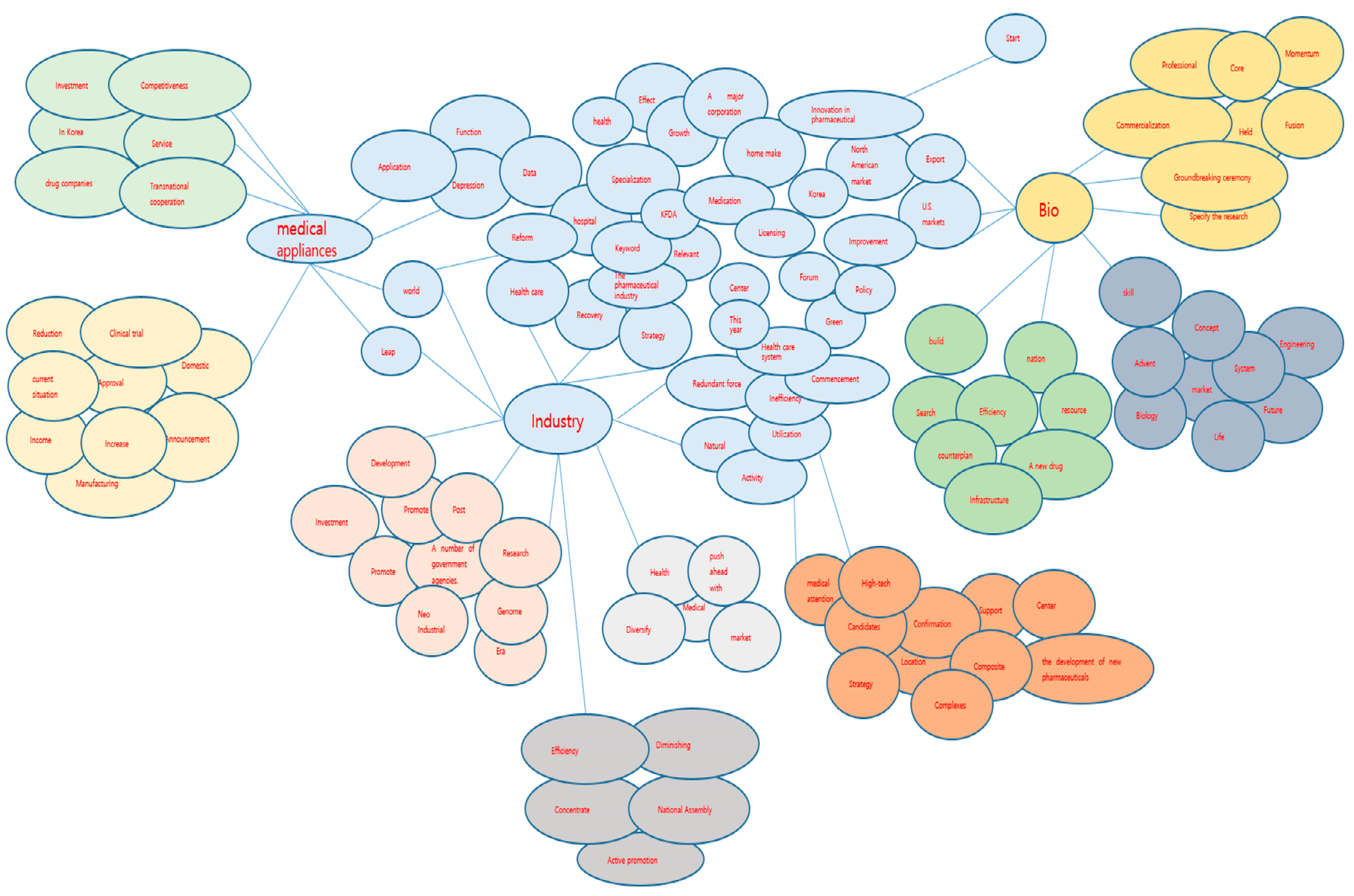

Figure 6. Bio-issue clustering by social network analysis. 


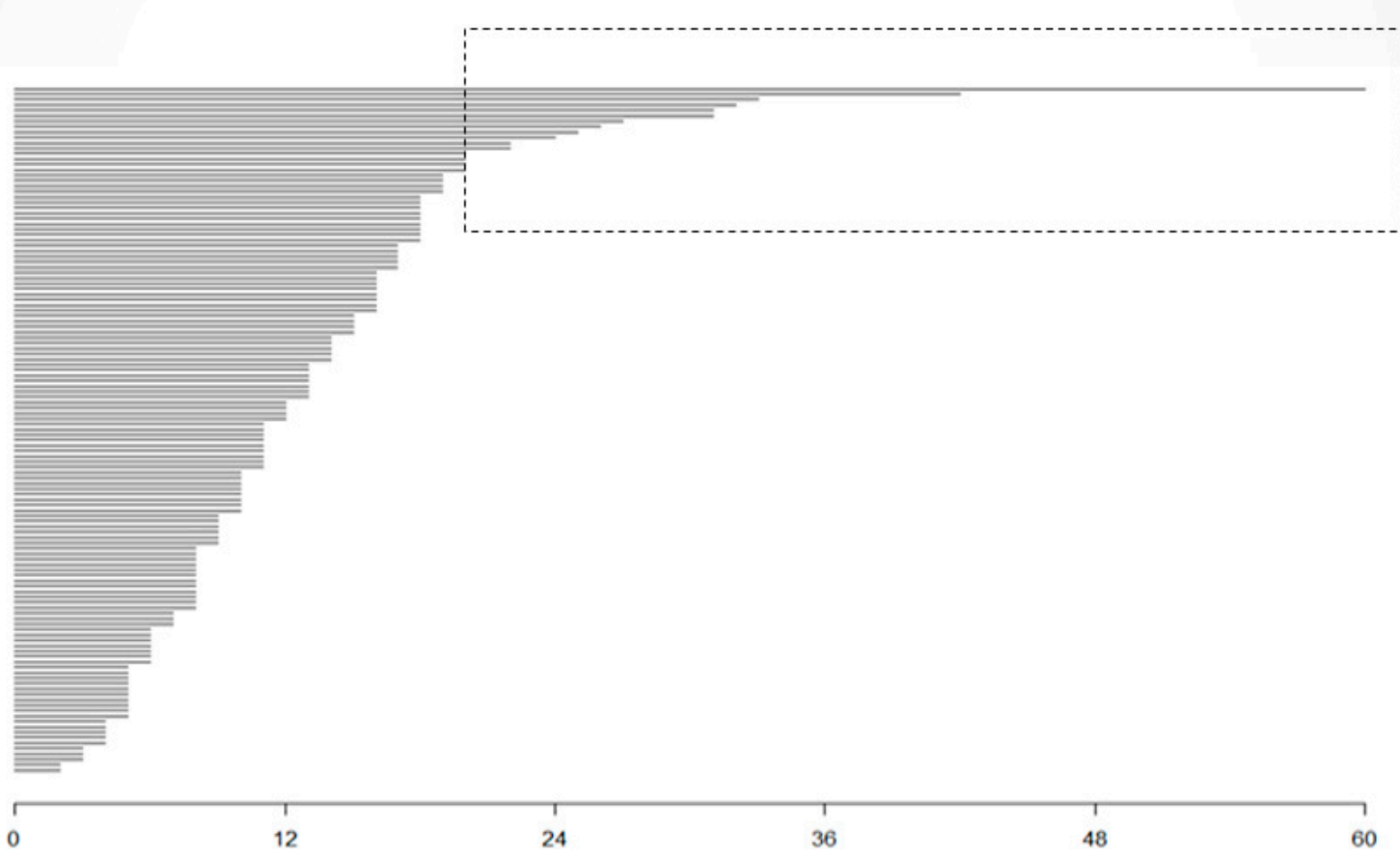

Figure 7. Barcode plot.

The ABM (agent-based model) for market needs management is based on a partial correlation between each factor signal. At each time step, the probability of each needs signal is calculated, which depends on the total activation of neighboring nodes in the previous period as well as the specific parameters. The individual application parameters depend on the slope and intercept of each factor. The activation probability for each factor can be expressed as follows:

$$
\operatorname{logit}(Y)=\ln (\text { odds })=\ln \left(\frac{\pi}{1-\pi}\right)=\alpha X-\alpha \beta .
$$

If we solve $\operatorname{logit}(Y)$ for $p-\operatorname{Probability}(Y=1 \mid X=x$, a specific value of $X)$, we obtain:

$$
\pi=\frac{e^{(\alpha X-\alpha \beta)}}{1+e^{(\alpha X-\alpha \beta)}}=\frac{1}{e^{-(\alpha X-\alpha \beta)}},
$$

where $\pi$ is once again the probability of the event, $a(=\alpha)$ and $b(=\alpha \beta)$ are regression coefficients, and $X$ is a set of predictors. Parameters " $a$ " (steepness) and " $b$ " (intercept) are typically estimated by the maximum likelihood methods. On the other hand, the parameter " $a$ " applied to the individual factor represents the slope of the probability function as shown in the above equation, and it can be multiplied by the total needs amount of the entire network to determine the entire needs change. The parameter " $b$ " is the needs-based threshold value (resistance value). Market needs with a higher threshold value require a greater intensity of stress to activate a signal with a lower threshold value (Table 5).

Figure 10 shows the hysteresis plot of the ABM. The histogram shows the frequency of activated needs factors. The following is an example of analysis according to two scenarios [14]. 


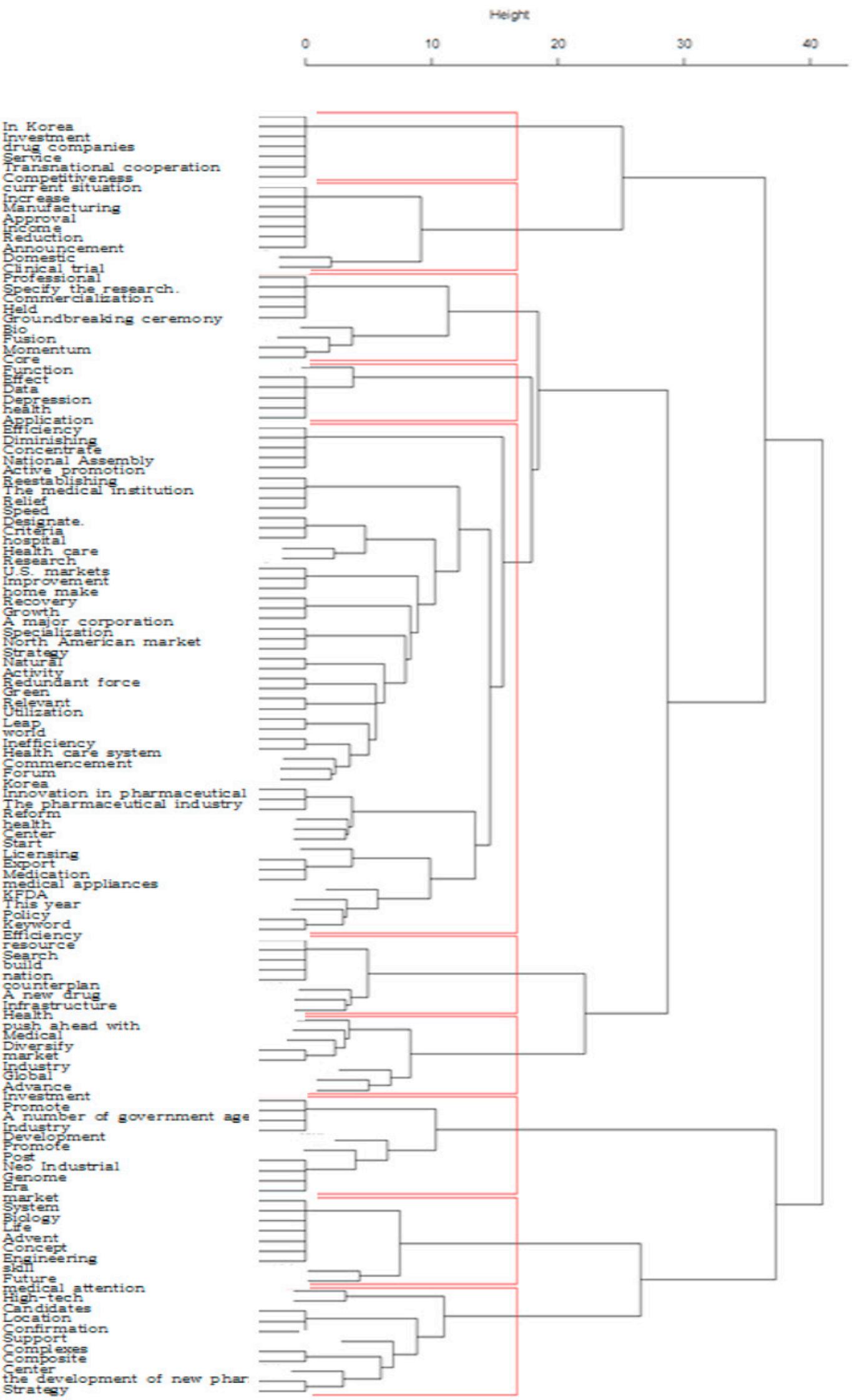

Figure 8. Hierarchical clustering with Euclidean distance. 


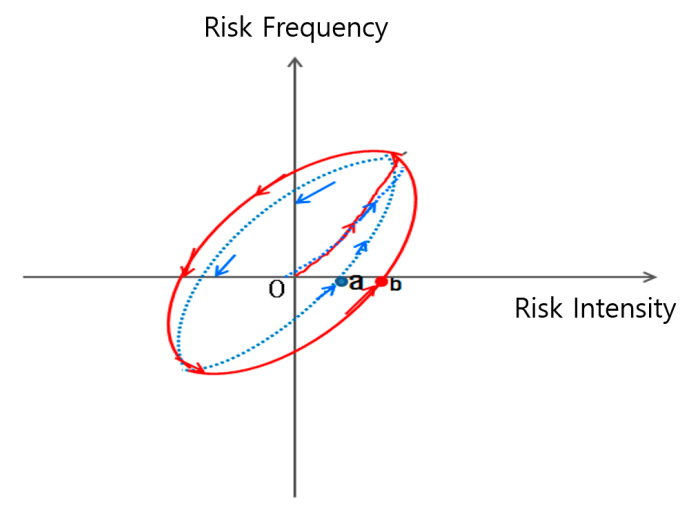

Figure 9. Conceptual illustration of hysteresis effect.

Table 5. Steepness and intercept of clusters.

\begin{tabular}{cccc}
\hline No. & Cluster & Steepness $(\boldsymbol{a})$ & Intercept $(\boldsymbol{b})$ \\
\hline 0 & Pharmaceutical investment & 0.2 & 0.7 \\
1 & Clinical infrastructure & 0.2 & 0.9 \\
2 & Bio-technology development & 0.2 & 0.9 \\
3 & Health food development & 0.2 & 0.6 \\
4 & R\&D investment & 0.1 & 1.4 \\
5 & Expanding commercialization & 0.1 & 2.2 \\
6 & Development of medical equipment & 0.1 & 1.5 \\
7 & New drug infrastructure & 0.2 & 0.8 \\
8 & Healthcare development & 0.2 & 0.8 \\
9 & Fostering new industries & 0.2 & 1 \\
10 & Technology development & 0.2 & 0.9 \\
11 & Medical complex development & 0.2 & 1.1 \\
\hline
\end{tabular}

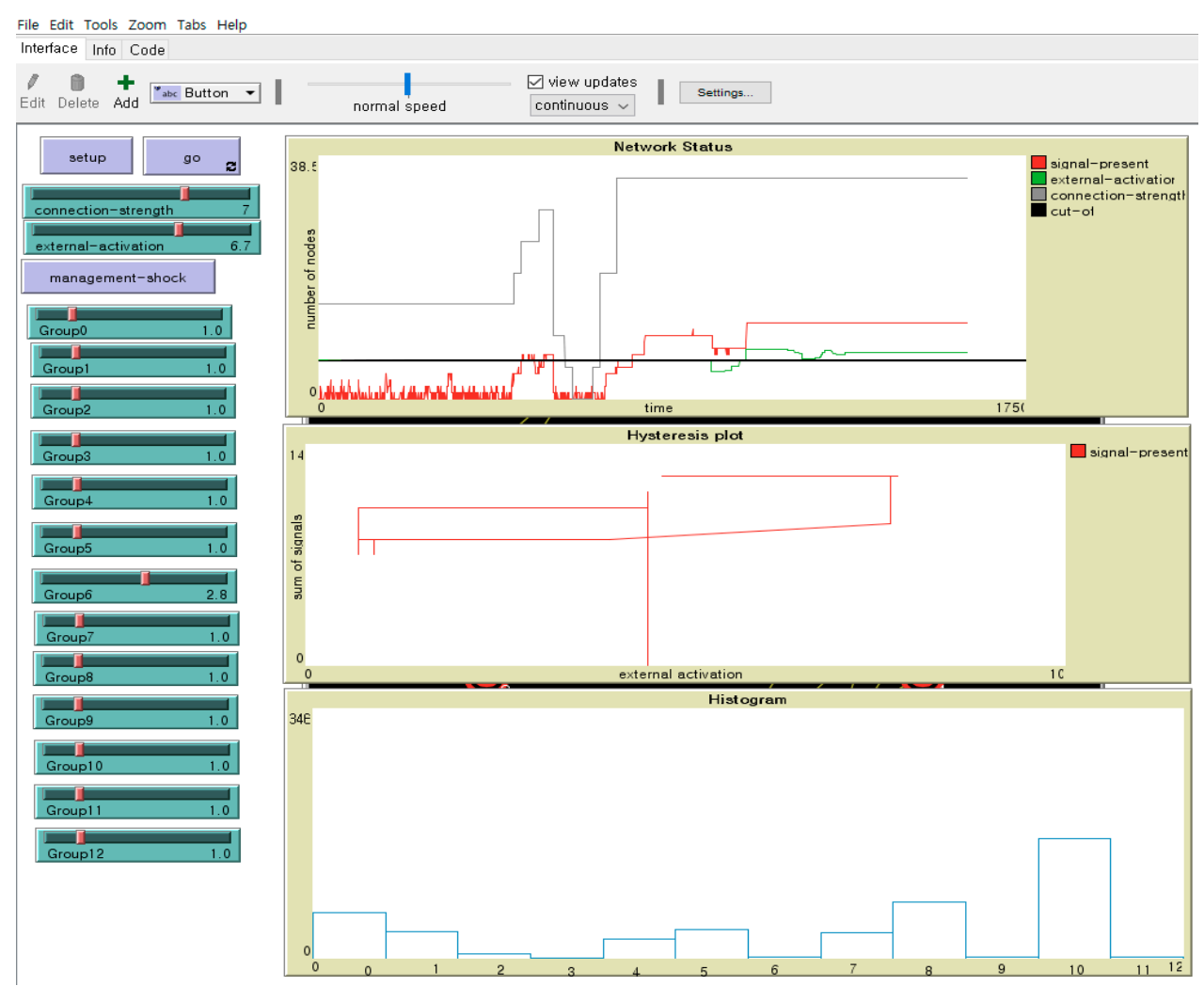

Figure 10. Screen of simulation model developed by ABM tool NetLogo. 


\section{Scenario 1}

When the intensity of connection between elements is changed, the demand frequency does not change even if the inter-element connection strength is increased above the demand excess threshold (cutoff: 8). Conversely, when the intensity of the connection below the threshold value is lowered, the demand frequency is relatively changed. Only the 7th factor (new drug Infrastructure) and the 8 th factor (healthcare development) have survived (Figure 11).

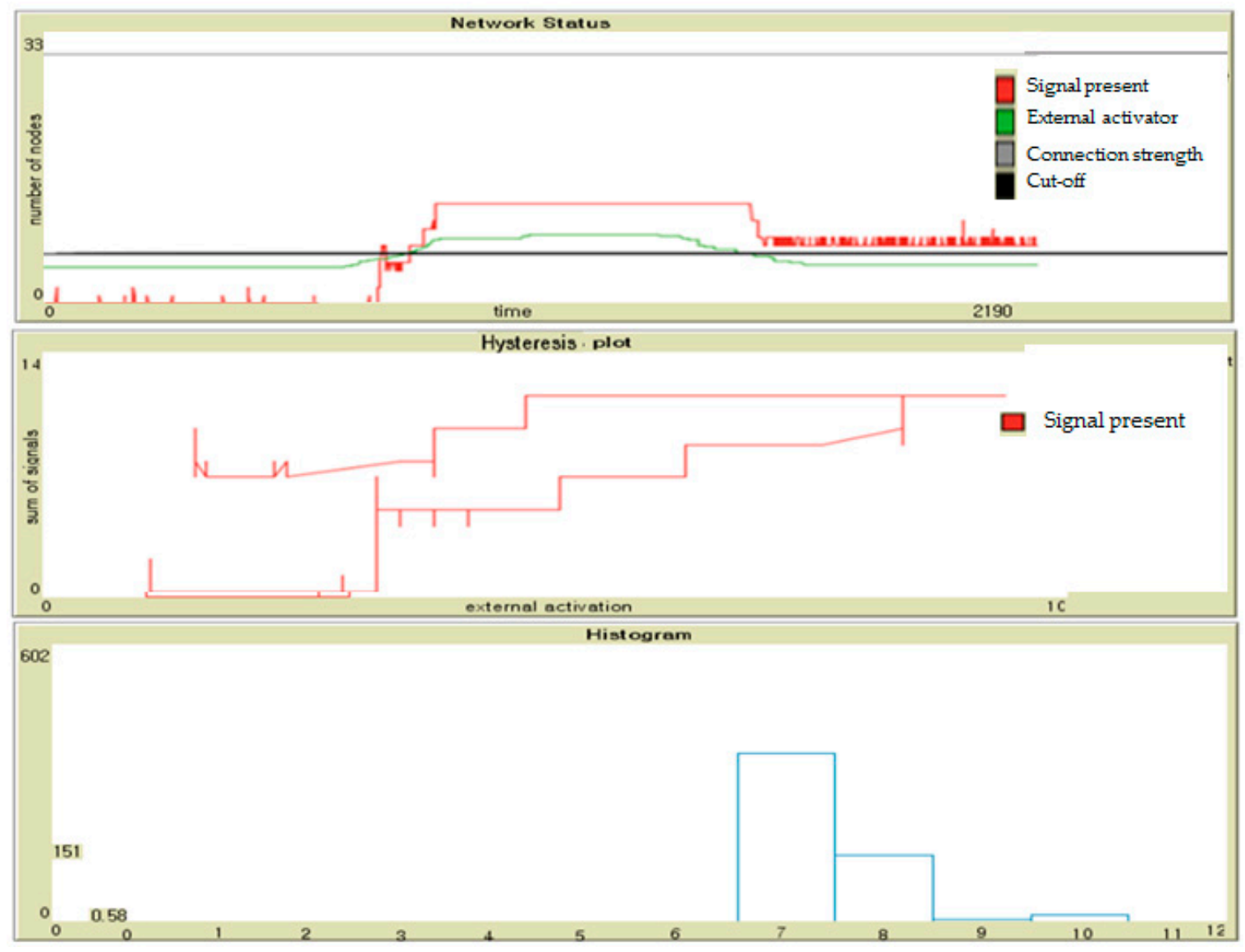

Figure 11. The case of changing the connection strength between the factors.

\section{Scenario 2}

In this model, we try to simulate the characteristics of the factors depending on the external impact strength. First, when external shocks are strong, the most frequent factors are 0th (pharmaceutical investment), 4th (R\&D investment), and 5th (expanding commercialization) (Figure 12). On the other hand, when the external shock was weak, no element was activated (Figure 13).

As described above, we found the following five of 12 major topics through hysteresis analysis: new drug infrastructure, healthcare development, pharmaceutical investment, R\&D investment, and expanding commercialization. By analyzing the common areas of these five topics, we selected the pharmaceutical market for our target market. As shown in Figure 14, the pharmaceutical market plays an important role in R\&D, commercialization, and infrastructure of healthcare systems in South Korea. 


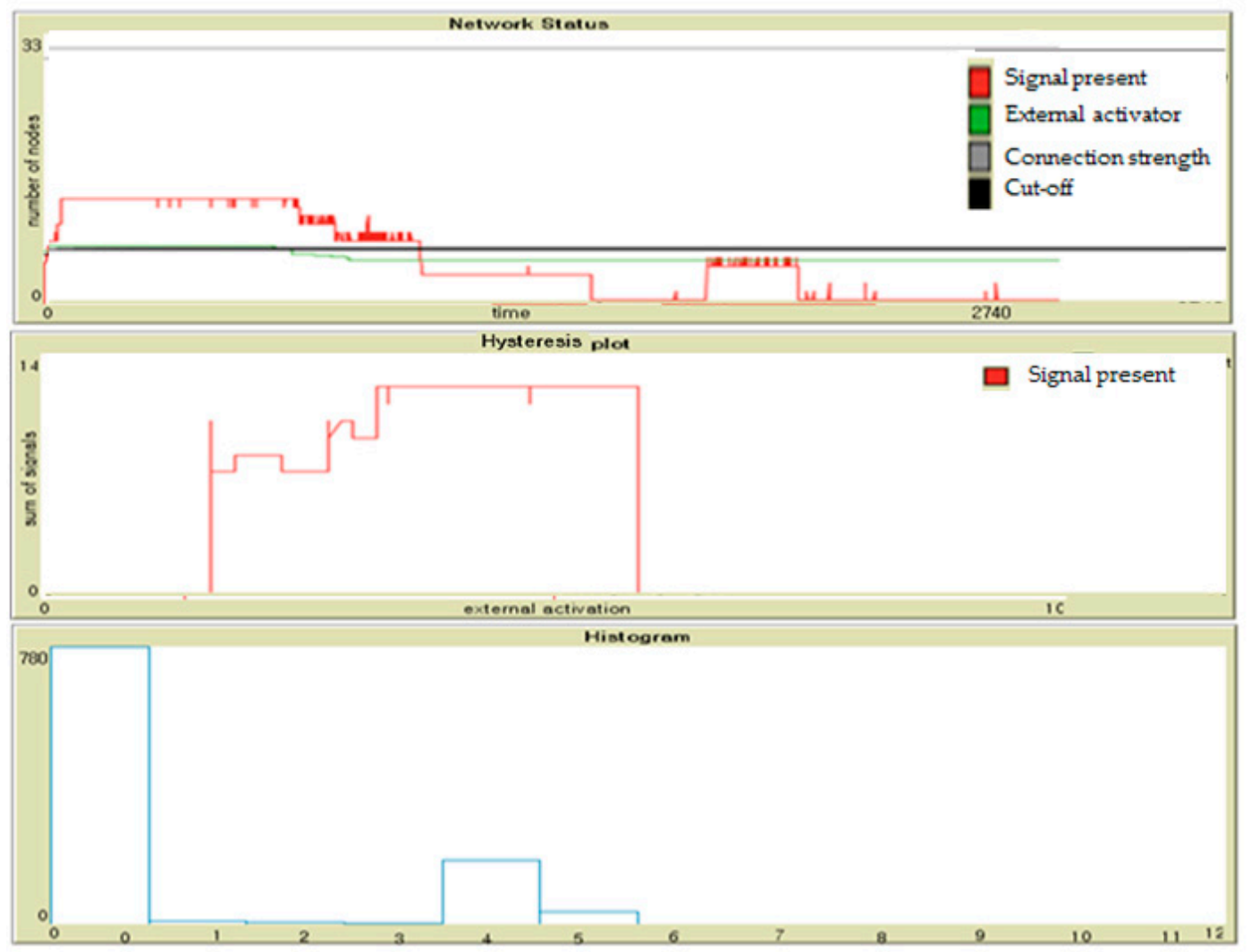

Figure 12. Comparison of hysteresis between factors when the external impact is weak.

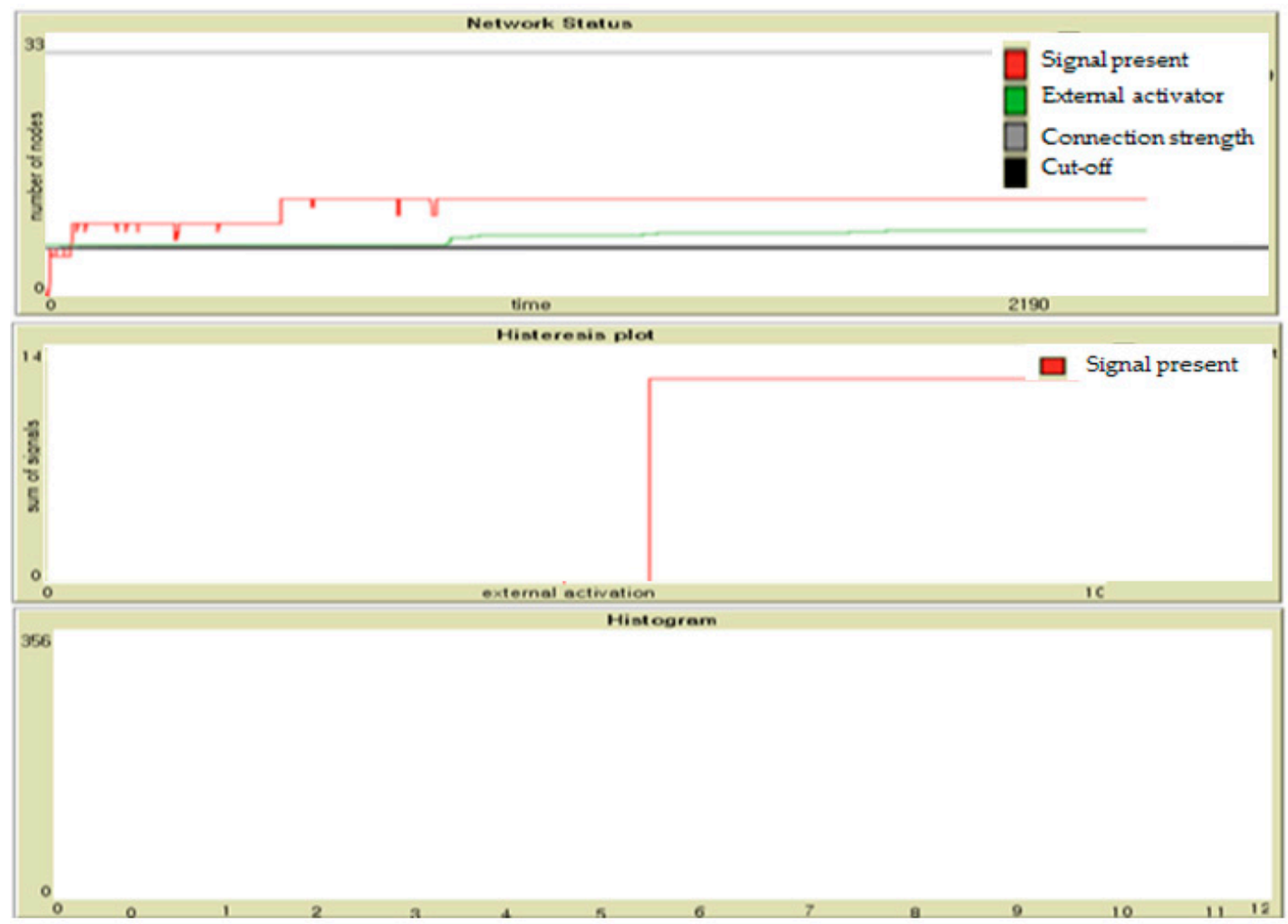

Figure 13. Comparison of hysteresis between factors when the external impact is strong. 


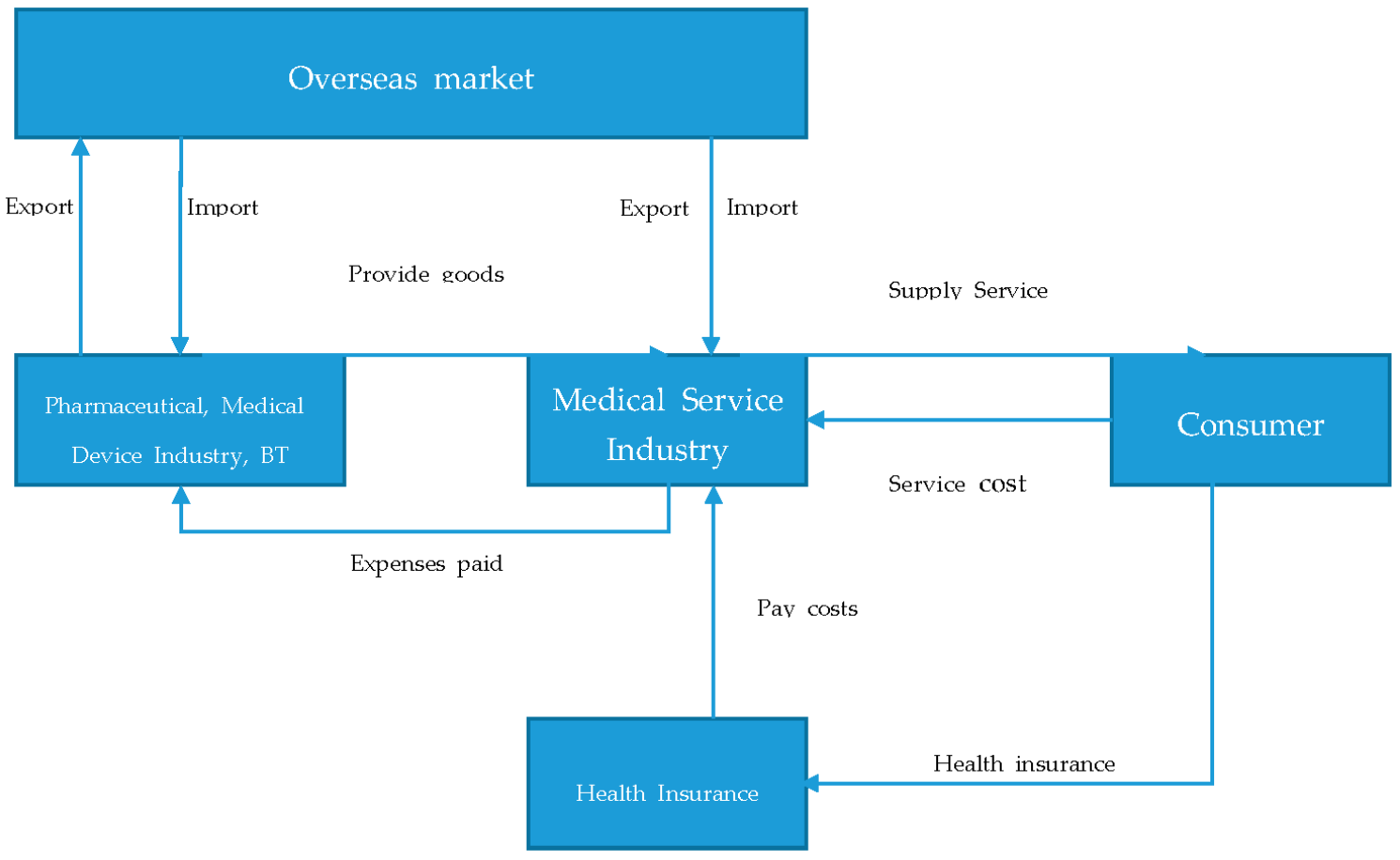

Figure 14. Healthcare systems in South Korea.

\subsection{Focus of Consumer Demands}

As mentioned above, we targeted the pharmaceutical sector, in which the factors of both growth and welfare coexist and are highly associated. Market intervention was carried out by the government through policy change. Policies were focused on new technologies for drug development (to increase the competitiveness of products) and those that improved the national protection and welfare of the country.

As mentioned earlier, the number of patients living with long-term chronic diseases is increasing rapidly due to the extension of human life. Furthermore, there have been social crises caused by sudden illnesses (i.e., swine flu) throughout the world. As such, policies on appropriate technology development and pricing have a powerful influence on increasing the sales of related companies, improving the quality of life of patients, and diffusing social unrest. In consideration of risks such as disasters (e.g., the sinking of the Sewol ferry in South Korea and the Middle East Respiratory syndrome (MERS)), the variable impact factors from both sociocultural and subjective perspectives, apart from a technical and scientific point-of-view, have become increasingly important [15].

We utilized the Agent-Based Model to study the relationship between happiness and maximum sales in a society and included corporations, consumers, and potential consumers in the investigation. This model is based on an individual's decision and allows for the measurement of changes in the system. We used different scenarios for creating policies and then evaluated them in relation to business success and the satisfaction of human needs. Ultimately, we analyzed the possibilities for enhancing both sustainability and social soundness. We did this by comparing policies focused on improving the success of businesses and consumer happiness.

\subsubsection{Model}

Human decisions, such as a purchasing decision, can be explained by analyzing a combination of uncertainties and risks with the Bayesian Probability Theory of multi-attribute utility. Through this process, the maximized effectiveness of various alternatives can be evaluated. This cognitive decision-making process can be divided into the following groups: the recognition step, 
information-gathering stage, alternative evaluation stage, purchasing, and post-purchasing stage [16]. In addition, when considering various alternatives, the purchasing decision is based on maximizing the value of goods by considering a number of the product's properties [17].

However, in the real market, these rational decisions are affected by both personal traits and socioeconomic interactions. Every individual has different motivations and buying behaviors based on external influences such as changes in technological innovation [18].

The purchasing decision is the sum of personal utility values for each product attribute. These values constitute an individual's rational desire for a product. The post-purchase evaluation of a product's attributes affects the personal utility of the product. In terms of the desirability of a product, an individual is affected by the people who are using that product, as manifested in social interactions. The motivation to buy a particular product is affected by a risk assessment in relation to social issues, such as epidemics of infectious diseases and the side effects of medications (Figure 15).

A consumer's purchasing decision can be expressed as the sum of values that are provided to the consumer by the utility of specific properties. Consumer $i$ 's utility for product $j$ that has the n-numbered attribute can be expressed as follows:

$$
\text { Utility }_{i, j}=\sum_{n} \mathrm{~A}_{n} \times \text { product attribute }{ }_{n}
$$

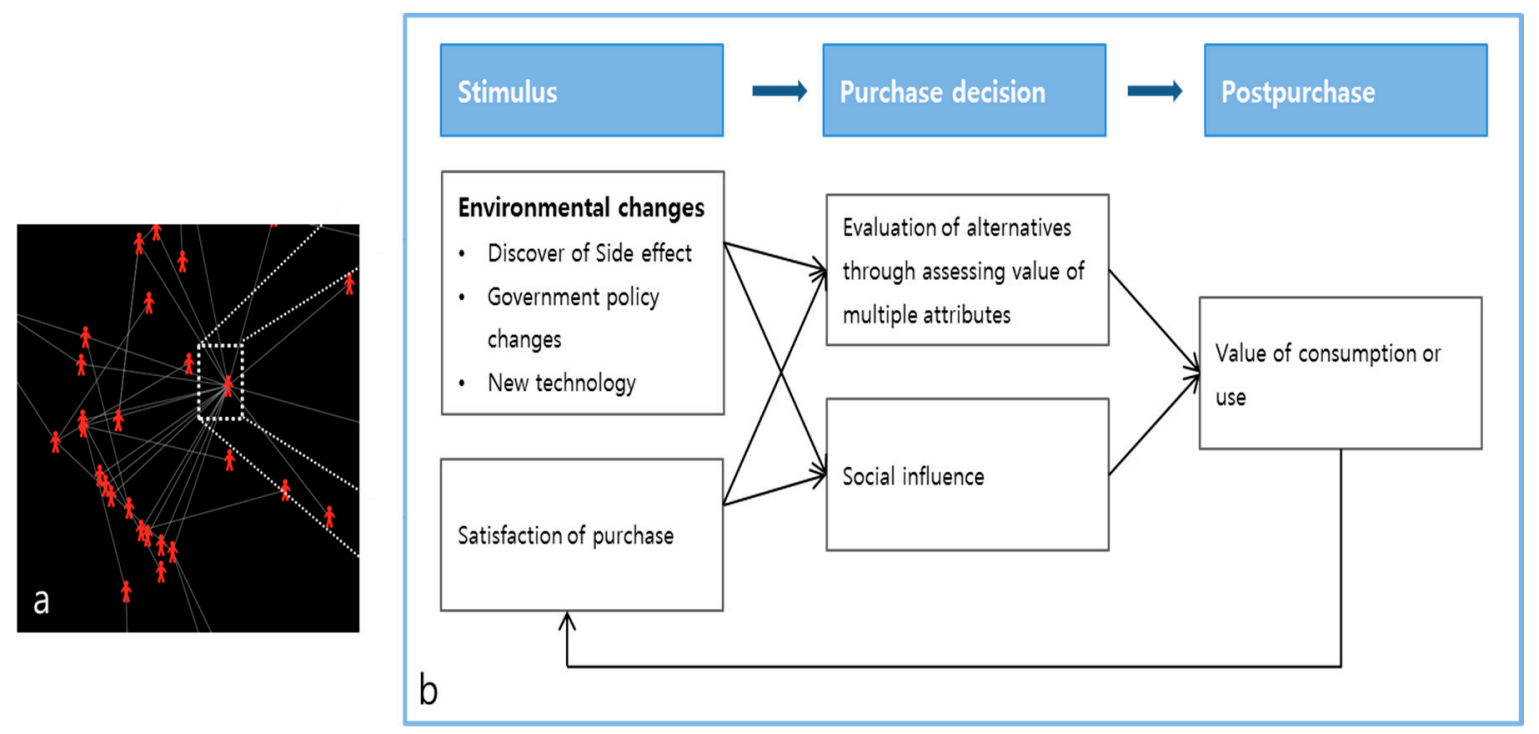

Figure 15. A consumer's purchasing decision process. (a) The model environment within which individual's purchasing decisions are made in social activities; (b) at the individual level, each customer has personal sensitivity to each attribute (price, brand, drug efficiency, convenience, etc.). Purchasing decisions and purchasing behavior were influenced by these individual characteristics and other people's stimuli within their social network system.

A product attribute refers to the $n$-properties of the product, such as price and brand. A is a coefficients of these independent properties of the product. The weights of major independent attributes, as well as attributes that were important in the decision-making process, were calculated using the conjoint analysis results in a pharmaceutical market (Table 6) [19]. Finally, the personal utility value was randomly distributed to provide diversity in the ABM model. 
Table 6. The weight of attributes for multi-attribute utility decisions.

\begin{tabular}{ccc}
\hline Attribute & Definition & Weight \\
\hline Brand & Brand awareness & 1.3 \\
Price & The money required to pay for a single dose of pills & 21.7 \\
Efficiency & Medical efficacy to decrease main symptoms of disease & 9.5 \\
Convenience & Improve convenience, including administration method, number, etc. & 7.1 \\
Side Effects & Unwanted non-therapeutic effects caused by a drug & 12.8 \\
Marketing & Advertisement to increase product awareness & 6.7 \\
\hline
\end{tabular}

Consumers, as actors interacting within a social network structure, are affected by the products selected by the people around them. The influence of surrounding people regarding product $j$ on consumers can be expressed as follows:

$$
\text { Social effect (Influence of surrounding people } \left.e_{i, j}\right)=\frac{\sum \text { Neighbor }_{i, j}}{\sum \text { Neighbor }_{j}+\Sigma \text { Neighbor }_{j^{\prime}}} .
$$

The purchasing decisions of consumers can be expressed as the sum of individual utility value and social effects:

$$
\text { Purchase decision }_{i, j}=\alpha^{*} \text { Utility }_{i, j}+\beta^{*} \text { Social effect }_{i, j} \text {. }
$$

We simulated a market model from a political perspective instead of a corporate marketing perspective. As such, the products were classified as market leading products, low-cost products, and new technological products rather than specific products from a particular company (Table 7).

Table 7. Classification and characterization of products.

\begin{tabular}{ccccccc}
\hline Product & $\begin{array}{c}\text { Price } \\
\text { (Won) }\end{array}$ & $\begin{array}{c}\text { Efficiency } \\
\mathbf{( \% )}\end{array}$ & $\begin{array}{c}\text { Dosing } \\
\text { Convenience }\end{array}$ & Side Effects & Brand & Marketing \\
\hline Market leading product (A) & $500 \sim 1000$ & 100 & No & Yes or No & High & High \\
\hline Low-cost product (B) & $500 \sim 600$ & 100 & No & Yes or No & Middle or Low & Middle \\
\hline New-technology product (C) & $600 \sim 1000$ & $100 \sim 200$ & Yes or No & Yes or No & $\begin{array}{c}\text { High, Middle, } \\
\text { Low }\end{array}$ & $\begin{array}{c}\text { High or } \\
\text { Middle }\end{array}$ \\
\hline
\end{tabular}

\subsubsection{Simulation of Agent-Based Model}

In this paper, we targeted the prescription drug market for high blood pressure for two reasons. First, high blood pressure increases significantly with the aging of the global population. Secondly, a large number of people in the elderly population have been greatly influenced by the development of new technologies for treating high blood pressure. Since this is a huge market, pharmaceutical companies continue to develop new products with unique competitive advantages. In fact, there are a number of products on the market at the same time with a variety of prices and various utility values. However, there are significant development costs associated with bringing new technologies to the point of clinical trials for proving safety and efficacy. Because of these barriers in bringing new technologies to market, governments support a variety of policies to foster their development. In addition, changes in the external environment, e.g., the emergence of new-technology products or a crisis that affects specific factors, cause changes in the value of products to consumers. Thus, both satisfaction and desire welfare are closely related to appropriate technological policy.

\section{Scenario 1}

When a global company has a monopoly with their market-leading product and it develops a new, low-price product, its brand and financial powers are relatively weak. To what extent can the market share of this low-price product grow? What is the best price point for sales and profits? If a 
policy on price support was introduced, what price point would be optimal for maximizing national happiness on a limited budget (Table 8)?

Table 8. Characterization of product in Scenario 1.

\begin{tabular}{ccccccc}
\hline Product & $\begin{array}{c}\text { Price } \\
\text { (Won) }\end{array}$ & $\begin{array}{c}\text { Efficiency } \\
\mathbf{( \% )}\end{array}$ & $\begin{array}{c}\text { Dosing } \\
\text { Convenience }\end{array}$ & Side Effects & Brand & Marketing \\
\hline Market-leading product (A) & 800 & 100 & No & No & Very High & High \\
Low-cost product (B) & $500 ~ 800$ & 100 & No & No & Low & Middle \\
\hline
\end{tabular}

As the price of the product decreased, the market penetration of the low-price product quickly increased over time (Figure 16A,B). Both the market share and sales of product B increased as the price was lowered. Interestingly, when calculating profit in consideration of its initial development costs, the best price point for sale was not the lowest price point. When we assumed a cost of 400 won, the best price for Product B for business success was 600 won (red star in Figure 16D).
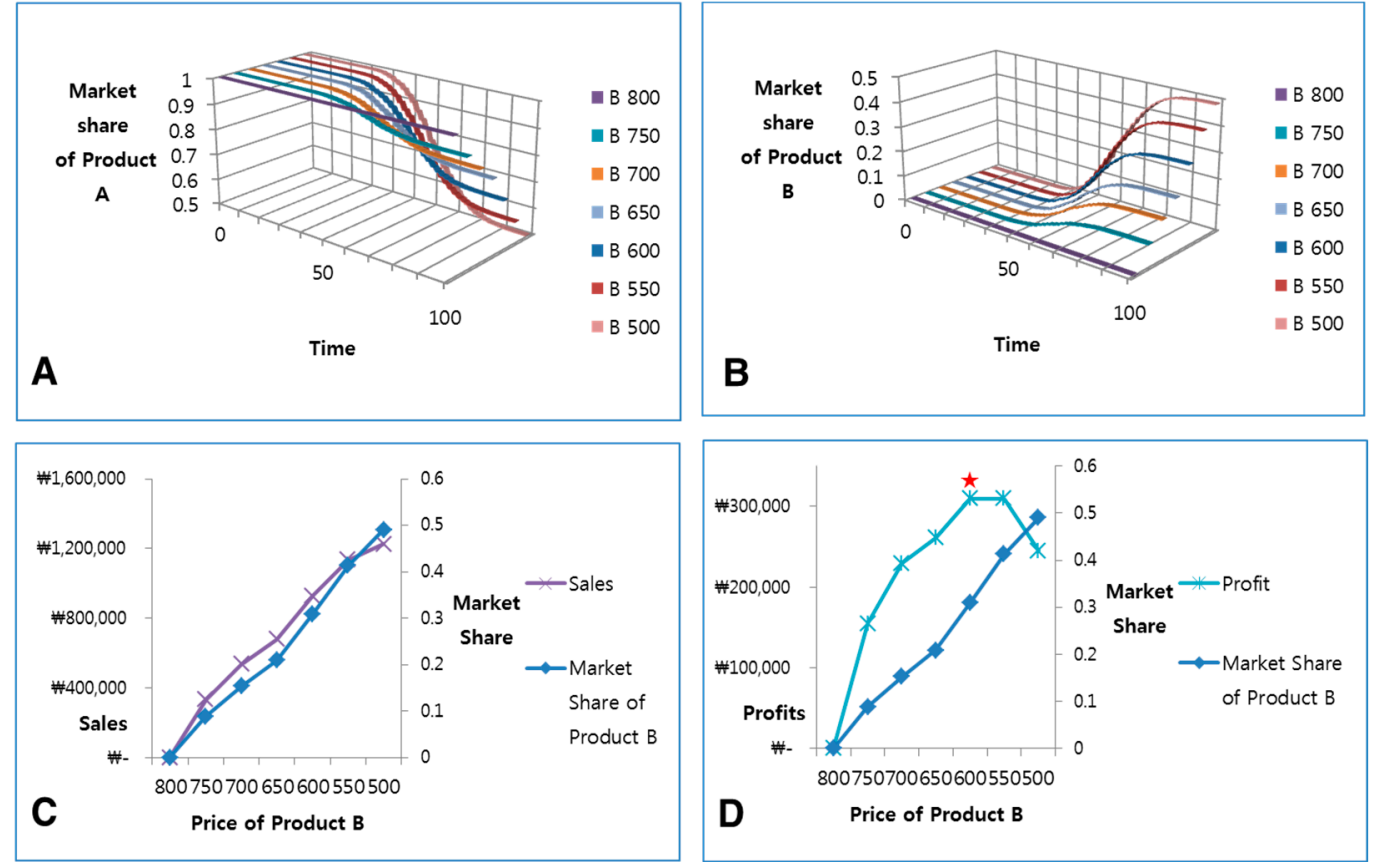

Figure 16. Changes of market share of Product A (A) and Product B (B) according to the price changes of Product B (low-price product, which entered market). Changes of market share, sales (C), and profits (D) of Product B in several conditions of Product B.

We next looked at the effect of introducing a pricing policy that supported the national welfare of elderly people through access to effective, affordable medications. The highest utility value was demonstrated when the price was dropped (with support from the budget) from 750 to 700 won (Figure 17). As such, 700 won is considered the optimal price point. By using this method of evaluation, the second optimal price point was determined to be 600 won. When the price of Product B was changed by policy within a society, the changes in utility values for Product B were calculated as follows:

$$
\begin{aligned}
& \text { Changed Utility Values for Product C B }= \\
& \frac{\sum \text { Utility Value for Product } B_{n}-\Sigma \text { Utility Value for Product } B_{n-1}}{\text { Price of } B_{n}-\text { Price of } B_{n-1}} .
\end{aligned}
$$




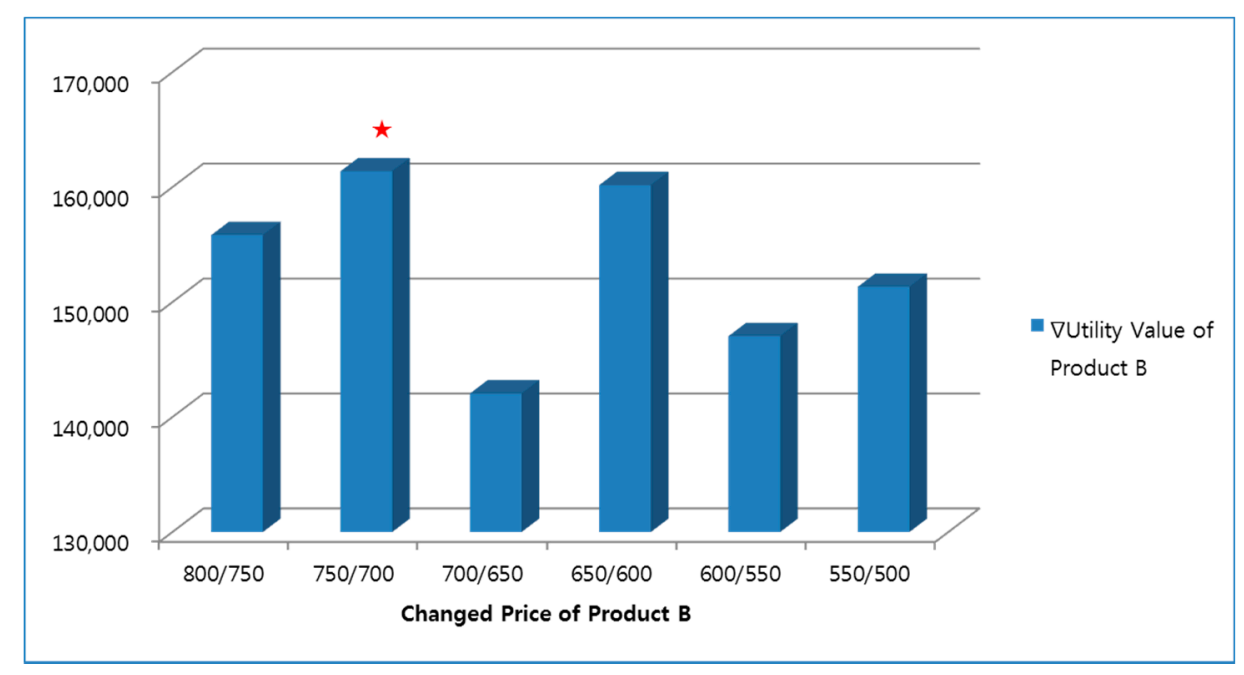

Figure 17. The sum of utility values for Product B in a society, according to the changes in price of Product B by introducing a pricing policy. When the price was dropped from 750 won to 700 won, the increase of utility values for members of society was highest (red star).

\section{Scenario 2}

Following the successful market penetration of a low-price product, a new-technology product was developed. Given several different conditions, what is the best technology policy to help this product enter the market or help existing companies retain their position in the market? The price of the low-price product was set at 600 won to maximize profits, while that of the market-leading product was set at 800 won (Table 9). Product B has $70 \%$ of the market share, while Product A has the remaining $30 \%$.

Table 9. Characterization of products in Scenario 2.

\begin{tabular}{ccccccc}
\hline Product & $\begin{array}{c}\text { Price } \\
\text { (won) }\end{array}$ & $\begin{array}{c}\text { Efficiency } \\
\text { (\%) }\end{array}$ & $\begin{array}{c}\text { Dosing } \\
\text { Convenience }\end{array}$ & Side Effects & Brand & Marketing \\
\hline Market-leading product (A) & 800 & 100 & No & No & Very High & High \\
Low-cost product (B) & 600 & 100 & No & No & Low & Middle \\
New-technology product (C) & $600 \sim 1000$ & 150 & No or Yes & No & Low & Middle \\
\hline
\end{tabular}

The reaction of the market to pricing changes of Product $C$ shows two inflection points (the dotted lines) (Figure 18A). When the price of Product $C$ is greater than 900 won, it is difficult for new-technology products to enter the market (Figure 18B); furthermore, low-price products dominate the market in this scenario. When the price of Product $C$ is between 750 and 850 won, Product $B$ is the most sensitive to changes in price of Product C (Figure 18C). This means that Product B is the main competitor within the price range of Product $C$. Interestingly, the rate of decrease in market share of Product A slightly slowed. When the price of Product $C$ fell below 700 won, the market share of Product $C$ rose steeply, while that of Product $B$ was not impacted. Also, the rate and speed of decline of market share of Product A were sensitive to the changes in price of Product C. In this scenario, Product $C$ rapidly replaced Product $A$ in terms of market share. 

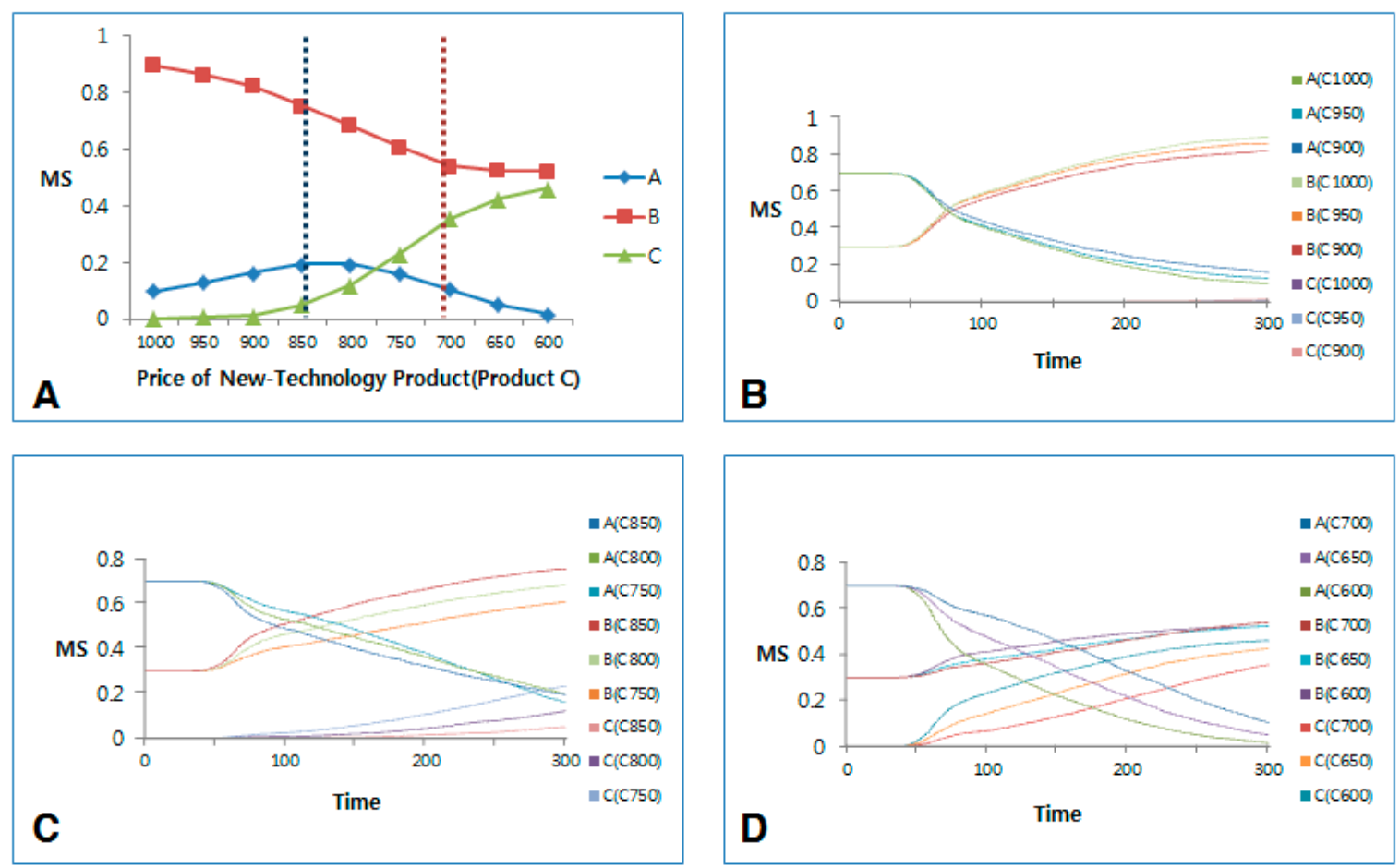

Figure 18. Changes of market share of Product A, Product B, and Product $C$ according to the price changes of Product $C$ (new-technology product, which entered market) (A). Changes of market share when the price of Product $C$ is greater than 900 won (B); when the price of Product $C$ is between 750 and 850 won (C); and when the price of Product $C$ is 700 won or less (D).

Assuming that the development of a new-technology product costs 500 won per product, the price point to obtain the best profit is 700 won (Figure 19).
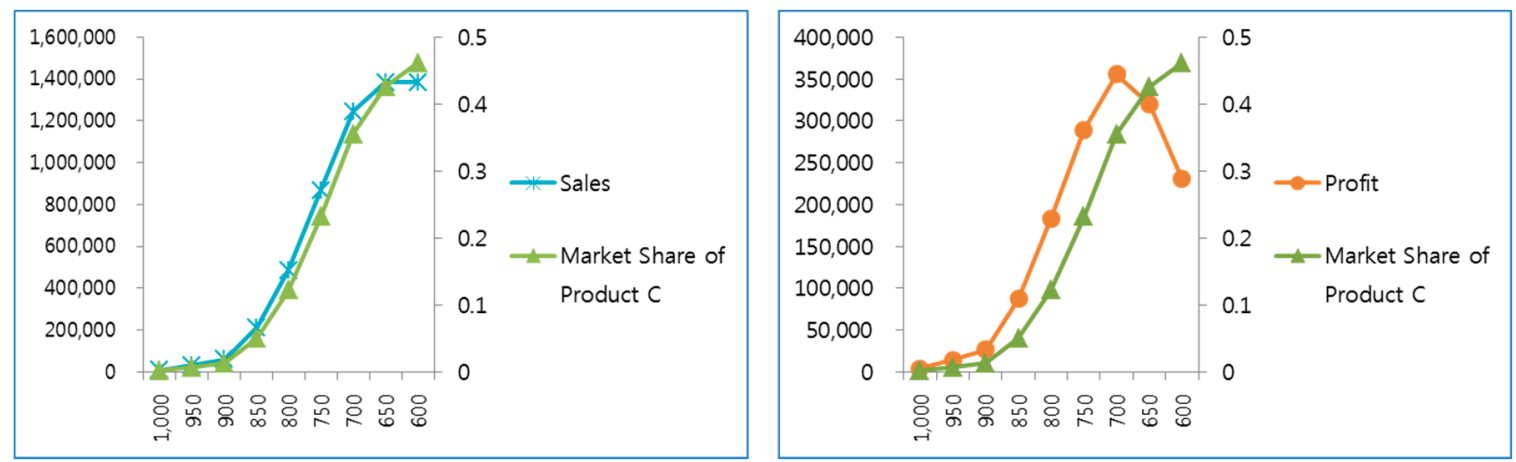

Figure 19. Changes of market share, sales (A), and profits (B) of Product $C$ according to the price changes of Product $C$.

Furthermore, if there is support for the price of the new-technology product, the optimal point for cost-effectiveness is 850 won (Figure 20). When the price of Product $C$ was changed by a policy that focused on welfare or on the development of new technologies in society, the changes in utility values were calculated as follows:

\footnotetext{
Changed Utility Values for Product $\mathrm{C}=$ $\frac{\Sigma \text { Utility Value for Product } C_{n}-\Sigma \text { Utility Value for Product } C_{n-1}}{\text { Price of } C_{n}-\text { Price of } C_{n-1}}$.
} 


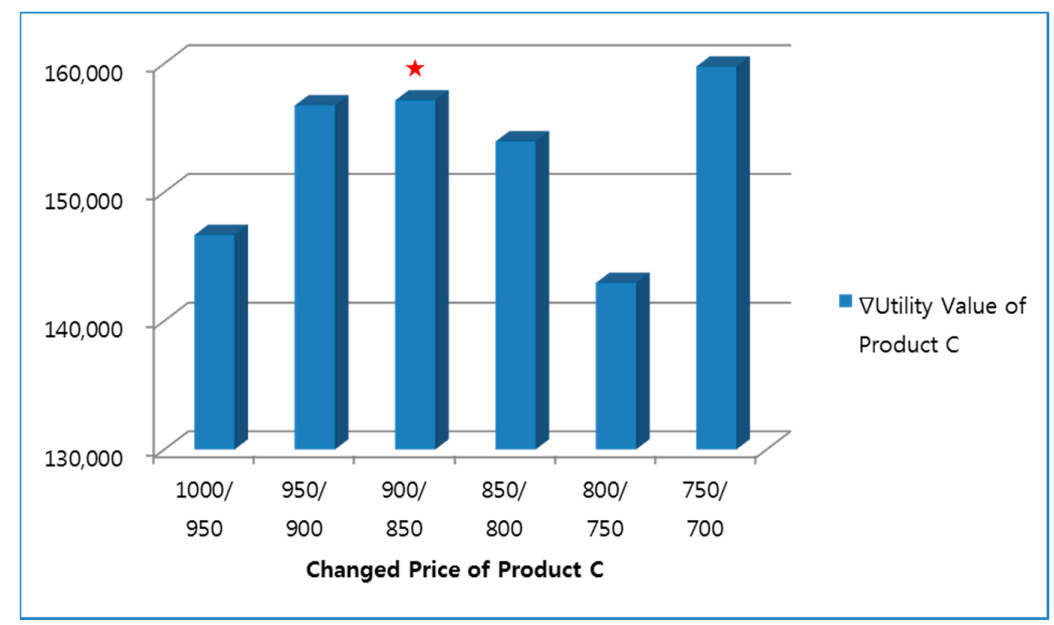

Figure 20. The changes of utility values for Product $C$, according to changes in the price of Product $C$.

If a company develops new technologies that meet a number of utilities, what is the impact on the market? We used the scenario of new technologies being developed for efficiency and dosing convenience.

Although two features were improved by new technological development, there were no significant differences in the pattern of market share compared to that of the previous technology product (Figures 21 and 22A). This demonstrates the importance of developing new technologies based on consumer needs in the market. Assuming that the initial cost is greater than the previous new-technology product, the cost must be at least 600 won (Figure 22B). In this case, the profit is approximately half that of the previous new-technology product and the appropriate price point is 750 won. However, if the initial cost is the same as the previous new-technology product (500 won), it is possible to have an optimal price of 700 won and slightly higher profits.
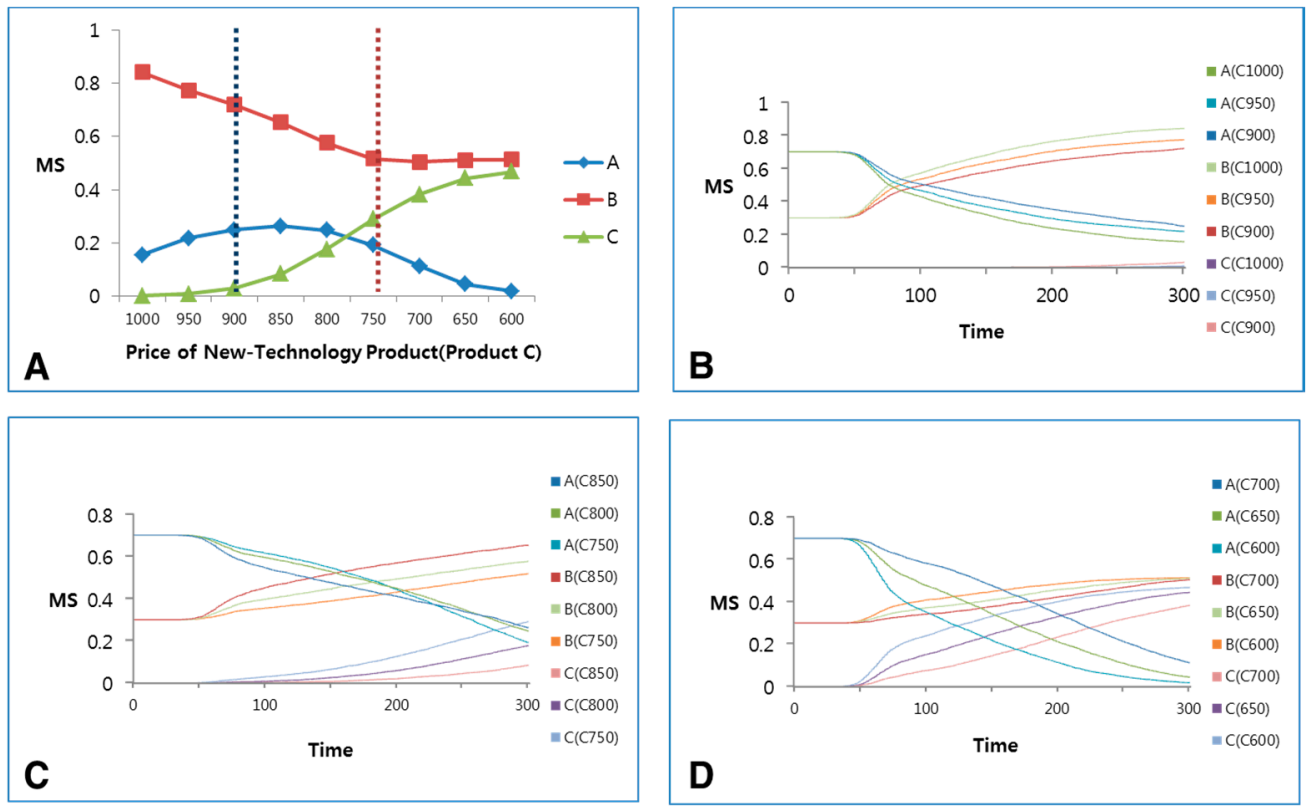

Figure 21. Changes of market share of Product A, Product B, and Product $C$ according to the changes in price of Product $C$ (new-technology product with improvements to two of its features) (A). Changes of market share when the price of product $C$ is over 900 won (B); when the price of Product $C$ is from 750 won to 850 won (C); and when the price of Product C is 700 won or less (D). 

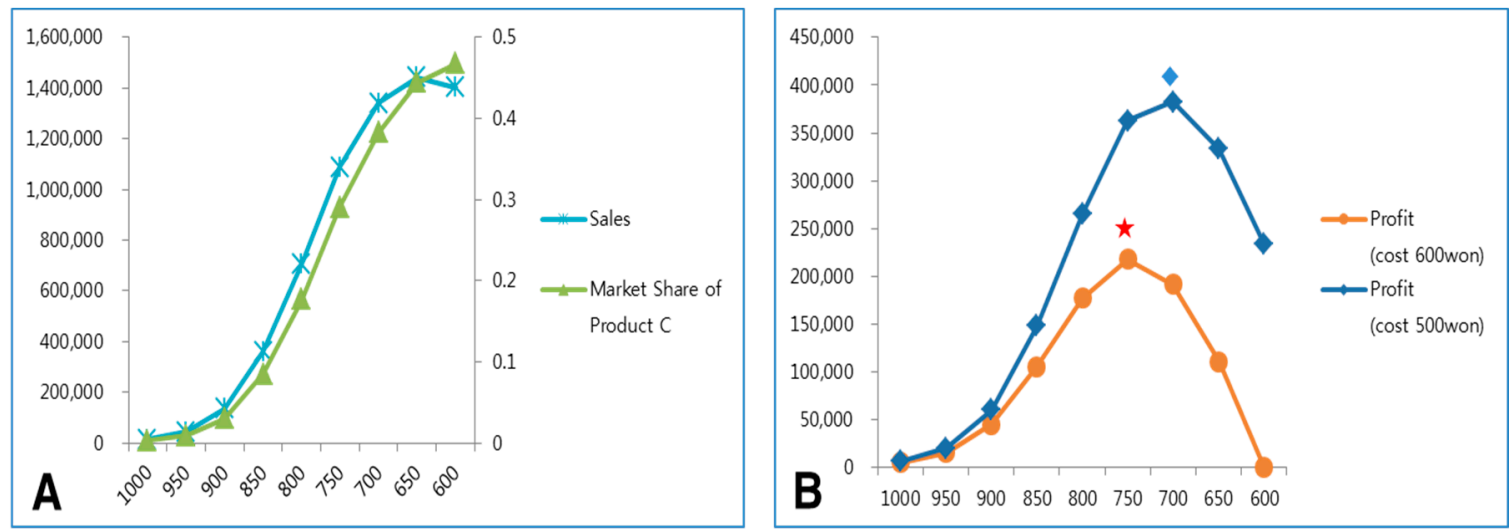

Figure 22. Changes of market share, sales (A), and profits (B) of Product C (new-technology product developed in two selected utility areas) according to the price changes of Product C.

\section{Conclusions}

In the existing literature, there were no examples of how human needs were reflected by the market and how technological and political policies affect the market share as well as the satisfaction of human desires and consequent happiness. In this paper, we have shown the dynamics of consumer decision-making processes in relation to technology products in the market. Also, we present a new marketing model based on human needs, wants, and demands, and focused on both holistic and social perspectives. We used the pharmaceutical market as an example to obtain a better national policy with regard to how human-happiness-based policy can impact the growth and sustainability of an industry.

We have shown that human-based policy dynamics and sustainable human happiness can be realized by stimulating national policies for consumer happiness in the human-needs-based sector (e.g., the healthcare industry). The overall impact of national policy on human happiness is stronger in these industries, where the gap between owned and currently offered products quickly shrinks.

This study has important implications for policymakers. The results of human happiness in the healthcare industry, as a barometer, may not only influence the sustainability of consumer satisfaction but also the creation of industrial policies. Forecasting the impact of national policy on human happiness and consumer satisfaction is crucial for designing sustainable $R \& D$ and for creating the right national vision.

A government's support for life-sciences research and innovation not only improves health outcomes domestically but also generates spillover effects, especially among a country's trade partners. However, it is difficult to uniformly apply the results of this study because people's needs differ according to the degree of economic growth of each country [20]. Therefore, future research should explore needs considering each country's political and economic context.

Acknowledgments: The Authors would like to thank the anonymous reviewers for their valuable comments, which greatly helped us to clarify and improve the contents of paper.

Author Contributions: The authors have been studying technology, society, and the market until recently through a complex society study group. Specifically, Jong-Yeon Lim developed the original idea for business success and human happiness in the market. DongKyu Won initiated this paper and gave guidance in the model. Sun Hi Yoo made contributions in data mining. All of the co-authors drafted and revised.

Conflicts of Interest: The authors declare no conflict of interest.

\section{References}

1. Veenhoven, R. Conditions of Happiness; Redel: Dordrecht, The Netherlands, 1984; pp. 22-24.

2. Khan, S.; Hussian, M. Determinants of Consumer Happiness and Its Role in Customer Loyalty. Int. Rev. Manag. Bus. Resear. 2013, 2, 11-19. [CrossRef] 
3. Seligman, M. Authentic Happiness; Free Press: Toronto, ON, Canada, 2002.

4. O'Brien, C. Sustainable happiness: How happiness studies can contribute to a more sustainable future. Can. Psychol. 2008, 49, 289-295. [CrossRef]

5. Steptoe, A.; Wardle, J.; Marmot, M. Positive Affect and Health Related Neuroendocrine, Cardiovascular, and Inflammatory Process. Proc. Natl. Acad. Sci. USA 2005, 102, 6508-6512. [CrossRef] [PubMed]

6. World Bank. World Development Indicators: Mortality. 2016. Available online: http://wdi.worldbank.org/ table/2.21 (accessed on 25 March 2016).

7. UN/Sustainable Development Solutions Network. World Happiness Report; UN/Sustainable Development Solutions Network: New York, NY, USA, 2016.

8. Veenhoven, R. Healthy Happiness: Effects of Happiness on Physical Health and the Consequences for Preventive Health Care. J. Happiness Stud. 2008, 9, 449-469. [CrossRef]

9. Brown, K.; Kasser, T. Are Psychological and Ecological Wellbeing Compatible? The Role of Values, Mindfulness and Lifestyle. Soc. Indic. Res. 2005, 74, 349-368. [CrossRef]

10. Stutz, J. The Role of Well-Being in a Great Transition; GTI Paper; Tellus Institute: Boston, MA, USA, 2006.

11. Grier, S.; Bryant, C.A. Socialmarketing in Public Health. Public Health 2005, 22, 319-339. [CrossRef] [PubMed]

12. Waterworth, E.L.; Waterworth, J.A. Focus, Locus, and Sensus: The Three Dimensions of Virtual Experience. Cyber Psychol. Behav. 2001, 4, 203-213. [CrossRef] [PubMed]

13. Yusr, M.M. Innovation Capability and Its Role in Enhancing the Relationship between TQM Practices and Innovation Performance. J. Open Innov. Technol. Mark. Complex. 2016, 2. [CrossRef]

14. Hair, J.F.; Ringle, C.M.; Sarstedt, M. PLS-SEM: Indeed a Silver Bullet. J. Mark. Theory Pract. 2011, 19, $139-152$. [CrossRef]

15. Won, D.K.; Yoo, S.H.; Yoo, H.S.; Lim, J.Y. Complex Adaptive Systems Approach to Sewol Ferry Disaster in Korea. J. Open Innov. Technol. Mark. Complex. 2015, 1. [CrossRef]

16. Engle, J.F.; Blackwell, R.D.; Miniard, P.W. Consumer Behaviour, 8th ed.; The Dryden Press: Fort Worth, TX, USA, 1995.

17. Keeney, R.L.; Raiffa, H. Decisions with Multiple Objectives-Preferences and Value Tradeoffs; Cambridge University Press: Cambridge, UK; New York, NY, USA, 1993.

18. Ajzen, I.; Fishbein, M. Attitude-Behavior Relations: A Theoretical Analysis and Review of Empirical Research. Psychol. Bull. 1977, 84, 888-918. [CrossRef]

19. Park, C. Analysis of Factors on Health Care Providers' Choice of Medicine: Focusing on Hypertension Medicine. Ph.D. Thesis, Kyoungsung University, Busan, Korea, 2012. (In Korean)

20. Maslow, A.H. Some Educational Implications of the Humanistic Psychologies. Harv. Educ. Rev. 1968, 38, 685-696. [CrossRef]

(C) 2016 by the authors; licensee MDPI, Basel, Switzerland. This article is an open access article distributed under the terms and conditions of the Creative Commons Attribution (CC-BY) license (http://creativecommons.org/licenses/by/4.0/). 